ECCOMAS

Proceedia
COMPDYN 2021

$8^{\text {th }}$ ECCOMAS Thematic Conference on Computational Methods in Structural Dynamics and Earthquake Engineering

M. Papadrakakis, M. Fragiadakis (eds.)

\title{
EVALUATION OF SEISMIC RESILIENCE OF RC-BUILDING SUBJECTED TO REPEATED EARTHQUAKE USING RESILIENT INDEX AND FRAGILITY SURFACE FUNCTIONS
}

\author{
Moustafa Moufid Kassem ${ }^{1}$, Fadzli Mohamed Nazri ${ }^{1 *}$ and Ahmad Mohamad El-Maissi ${ }^{1}$ \\ ${ }^{1}$ School of Civil Engineering, Universiti Sains Malaysia, Engineering Campus, 14300 Nibong \\ Tebal, Penang, Malaysia. \\ e-mail: moustafa-kassem@outlook.com \\ missi_1993@hotmail.com \\ *cefmn7@gmail.com / cefmn@usm.my
}

\begin{abstract}
Seismic resilience is a modern approach that aims to return the community of damage to its natural condition in a shortest possible time. Seismic resilience could be interpreted as a structure's ability to maintain a degree of functionality over a particular period of time once it is exposed to seismic events. The research study aims to address with an approach of functionality and seismic resilience of a mid-rise Ordinary Moment Resisting Frame (OMRF) structure subjected to repeated earthquakes. Besides, as a vulnerability and functionality study for risk assessments, both the Seismic Resilience Index (SRI) and the fragility surface were used to determine the seismic resilience of the selected building. The fragility surfaces expressed the probability of damages with respect to intensity measure and seismic event period (T). The concept phases of this approach were as follows: (1): Select targeted buildings, (2): Select and scaled a set of repeated Seismic Ground Motion (SGM) records, (3): Generate an Incremental Dynamic Analysis (IDA), (4): Fragility surface and (5): Functionality curve, with seismic resilience index (RI). Eventually, after investigating the structure through the vulnerability assessment, initiating with IDA, and ending with the fragility surface, it is clearly established that the buildings do not have the capacity to withstand a $15 \mathrm{sec}$ repetitive earthquake due to their ordinary structural design related to ductility demand. Meanwhile, with an increase in the possible seismic ground acceleration, the fluctuation in functionality, SRI, robustness, structural losses, and time recovery of distinct performance levels could be estimated.
\end{abstract}

Keywords: Seismic Resilience Index, Repeated Earthquake, Fragility Surface, Functionality Curve, Damage State, Structural Losses. 


\section{INTRODUCTION}

In the last decades, the intensity and frequency of earthquakes has increased, causing severe destruction with enormous number of casualties, posing a main disruption and change in the economic, social, and technical conditions for specific communities. Due to this fact, 'resilience', 'vulnerability', 'risk reduction', and 'recovery' definitions are trending in research community. However, it is vital to conduct a quantitative procedure to evaluate these intuitive definitions [1].

All these lead to the development of a resilience assessment for earthquakes by using a specific index, which is considered an important factor for managing and planning natural disasters. The main idea of resilience at the beginning was developed by ecologists, however, it expanded to a wider range of fields i.e., social science, psychology, and engineering [2].

The Seismic Resilience Index (SRI) is considered a powerful tool to demonstrate the capability of a structure to sustain a particular standard of performance and usability across a span of time control ( $\left.\mathrm{T}_{\mathrm{LC}}\right)$ [3]. Bruneau et al. [4] introduced a very general definition for resilience, which covered all the precautions that should be taken to reduce the main losses resulting from hazards, and also the study covered the effects of mitigation and recovery. After this broad definition that was introduced by Bruneau and Reinhorn [5], many studies were produced tackling the development and assessment of resilience.

Samadian et al. [6] conducted a study in Iran to determine the seismic resilience of built and rehabilitated RC school buildings, whereby the study was assessed through utilising vulnerability and fragility curves. The main objective of this study is to implement a new approach which focuses on provincial economic conditions, through the use of vulnerability analysis to estimate earthquake-related losses. The results showed that when the magnitude of hazard levels was increased the SRI decreased functionally. The study concluded that retrofitted school buildings had a higher resiliency level. Furthermore, the comparative study between fragility and vulnerability curves showed that the vulnerability curve indicated more efficient results to evaluate the SRI.

Furthermore, Vona et al. [7] introduced a new resilience approach for communities based on numerical assessment and observed post-seismic restoration procedure. The study focused on the housing systems to develop SRI for the communities, by which it was expressed as a combination of SRIs for each building category. The proposed approach could help in assessing different scenarios with more precise results, which could be achieved with more potential choices.

Titi and Biondini [8] tested the reliability of concrete frame structural systems that were affected by corrosion. The results showed that the designed structures designated to have the same level of functionality could display different seismic resilience over a specific time span resulting from the surrounding environmental conditions. Other studies were established to assess resiliency and calculate the SRI for different type of structures. For instance, Alipour and Shafei [9] assessed the seismic resilience transport networks and Banerjee and Chandrasekaran studied the seismic resilience of bridges under the effect of multi-hazards [10].

In addition, Cimellaro et al. [1] introduced a framework for analytical quantification of disaster resilience. This research focused on integrating information from different fields, which were earthquake engineering, social sciences, and economics to develop a disaster resilience framework. The main outcome of this study was to build a decision-making tool that could help both the policy makers and the engineering professionals for better preparedness and restoration plans after disasters. 
Various studies tackled the development and assessment of SRI and covered different categories and indicators [11-13], however, the studies that focus on the assessment and development of SRI under repeated earthquakes are limited.

Repeated earthquakes represented two or more incidents, which precisely hit the same fault area and slip, by which it generated the same waveform [14]. The repeated earthquakes could cause a significant deterioration and higher displacement demand for buildings. All these factors could directly impact the resiliency of these buildings [15-17]. Uchida [18] conducted a study to detect the repeated earthquakes and their application in characterising slow fault slip. The author concluded that by measuring the degree of waveform similarity and accurate hypocentre positions could help in recognising the repeated earthquakes and it could assist in evaluating the source-overlap ratio. The fragility curve or surface is considered as an efficient tool to study the effect of repeated earthquakes.

In seismic risk assessment, fragility curves are considered an essential element, which is defined by relating a given level of seismic intensity to the possibility of reaching or exceeding a certain degree of damage. To determine the performance limit states in relation to the Performance Based Seismic Design (PBSD) during earthquakes, structural damage was measured based on the Engineering Demand Parameters (EDP), i.e., vertical displacements, crack patterns or rotations. To establish fragility curves, which are empirical, theoretical, judgmental, and hybrid, different approaches could be used. [19, 20].

The fragility curve is usually defined by one parameter i.e., PGA, Sa, and Arias, but one distinct parameter is insufficient to study the effect of earthquakes on the buildings precisely. From here came the idea of developing fragility surface, by taking into consideration more than one parameter at the same time when studying the effect of the earthquake [21-23]. Many studies developed fragility surface to assess seismic risk on structures. For example, Ardebili and Saouma $[24,25]$ developed seismic fragility surfaces to study the effect of earthquakes on concrete dams, and Gehl et al. [26] developed fragility surfaces to evaluate the seismic vulnerability assessment for masonry buildings.

This leads to exploring the fact that lends the rise to the significance of seismic resilience and functionality, and the vulnerability risk assessment by using fragility surface. The aim of this paper is to shed the light on studying the seismic vulnerability assessment for an Ordinary Moment Resisting Frame (OMRF) structure that was designed away from any seismic attention under repeated earthquakes. This paper discusses the procedure for combining the vulnerability analysis to know the possibility of damages for four damage states, namely immediate occupancy (IO), damage control (DC), life safety (LS), and collapse prevention (CP), with the functionality of the structure post seismic event in respect to recovery time. Each damage states corresponds to an intensity measure to be determined by using the incremental dynamic analysis (IDA), and fragility surface. From the damaged states the preparedness of recovery procedure was adopted into three retrofitted actions. Firstly, no actions had been taken related to IO; secondly, the action was to apply a retrofitted application related to DC and LS; and thirdly, the action was at the replacement restoration process at CP level. Eventually, the SRI, functionality, loss of resilience and robustness were determined. 


\section{CONCEPTS OF SEIMSIC RESILIENCE INDEX (SRI)}

The Seismic Resilience Index (SRI) is considered as the main tool for studying the building ability to tolerate a particular standard of performance and reliability across a broad time control $\left(\mathrm{T}_{\mathrm{LC}}\right)$. In this paper, the SRI will be developed through applying different steps. Firstly, a model will be developed to the selected building by using finite element platform. Thereafter, ground motions for repeated earthquakes will be selected. Then, the IDA will be performed. This will all lead to the development of fragility surfaces and vulnerability curves. Finally, the functionality curve will be produced, which will help in estimating the SRI, Robustness (R), and Losses of Resilience (LOR). In order to develop the SRI and its functionality curve Q (t) the following steps should be tracked as shown and illustrated in Figure 1. Each step will be discussed in detail in the following section.

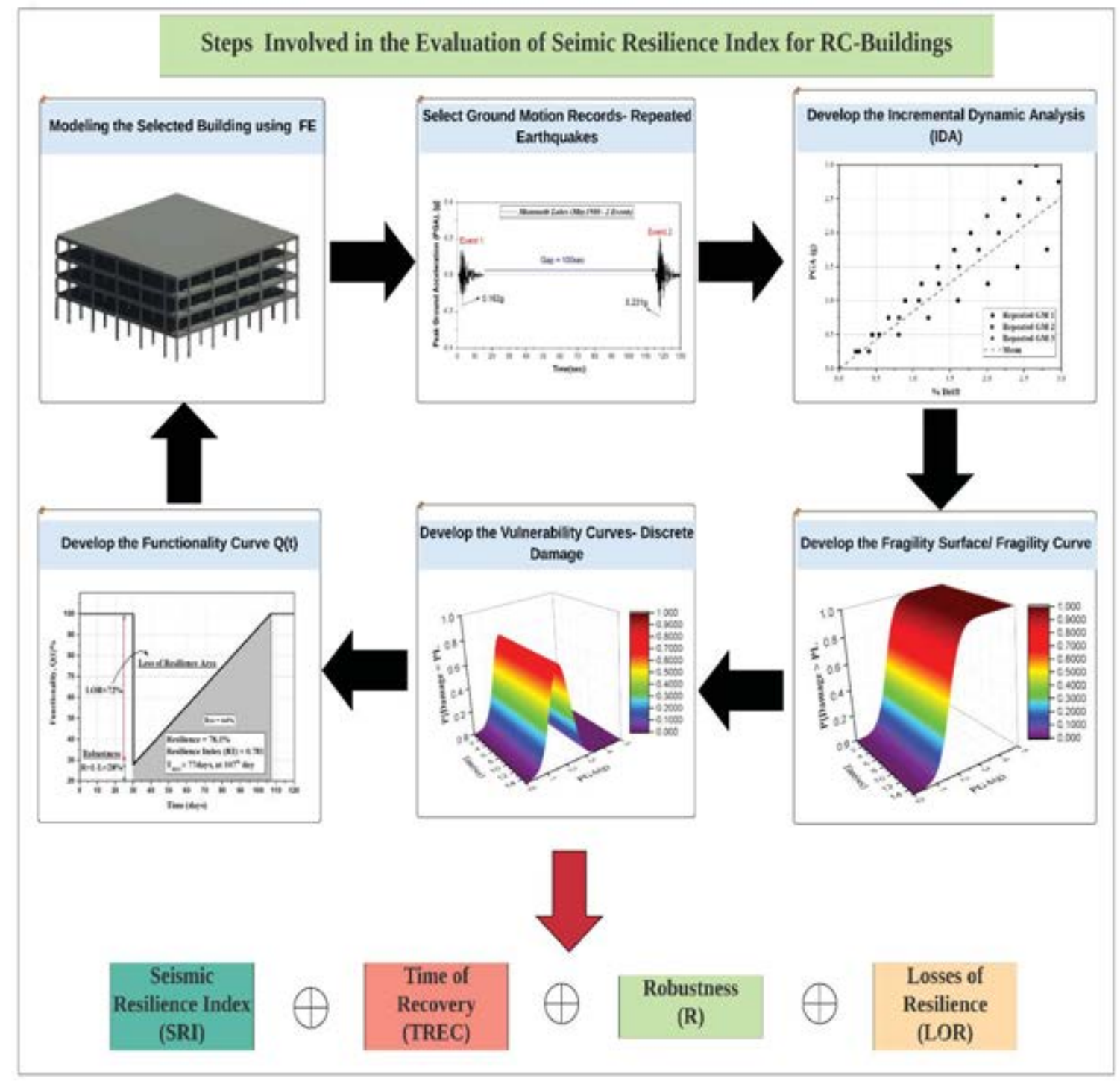

Figure 1: Framework steps for developing SRI. 


\subsection{Modelling structural configuration}

A mid-rise model of a 4-storey reinforced concrete building with a total height of $12.0 \mathrm{~m}$ and with a common slab thickness of $200 \mathrm{~mm}$ was considered in this study. The structural system selected for lateral resistance is considered as Ordinary Moment Resisting Frame (OMRF). The model was designed according to the regulation of ACI318-14 code for gravity loads, and for UBC1997 as OMRF for seismic loads. With reference to the seismic code, the building was assumed to be in seismic zone 4 , having soil profile $\mathrm{SD}$, with $\mathrm{Ca}=0.44$, and $\mathrm{Cv}$ $=0.64$ seismic coefficients.

The building materials used were $35 \mathrm{MPa}$ of concrete compressive strength ( $\mathrm{f}^{\prime} \mathrm{c}$ ), and yielding strength (fy) of $420 \mathrm{MPa}$ for the reinforcing steel bars. The gravity loads consisted of dead load and live load which was taken as $2 \mathrm{kN} / \mathrm{m}^{2}$, and $4 \mathrm{kN} / \mathrm{m}^{2}$, respectively. The columns cross sections were selected with dimensions of $300 \mathrm{~mm} \times 300 \mathrm{~mm}$, with drop beams of $300 \mathrm{~mm} \times$ $500 \mathrm{~mm}$. The design calculations supported the use of minimum reinforcement ratio for column longitudinal rebars, which was $1 \%$, whereby $8 \mathrm{~T} 12$ was used for column reinforcements, with T8 spaced every $300 \mathrm{~mm}$ as transversal reinforcement. For the beams, the design expressed the use of 3T12 as bottom longitudinal reinforcement, and 2T12 as top reinforcement. Figure 2 shows the targeted selected building model in three-dimensional (3D) shape, and elevation views.
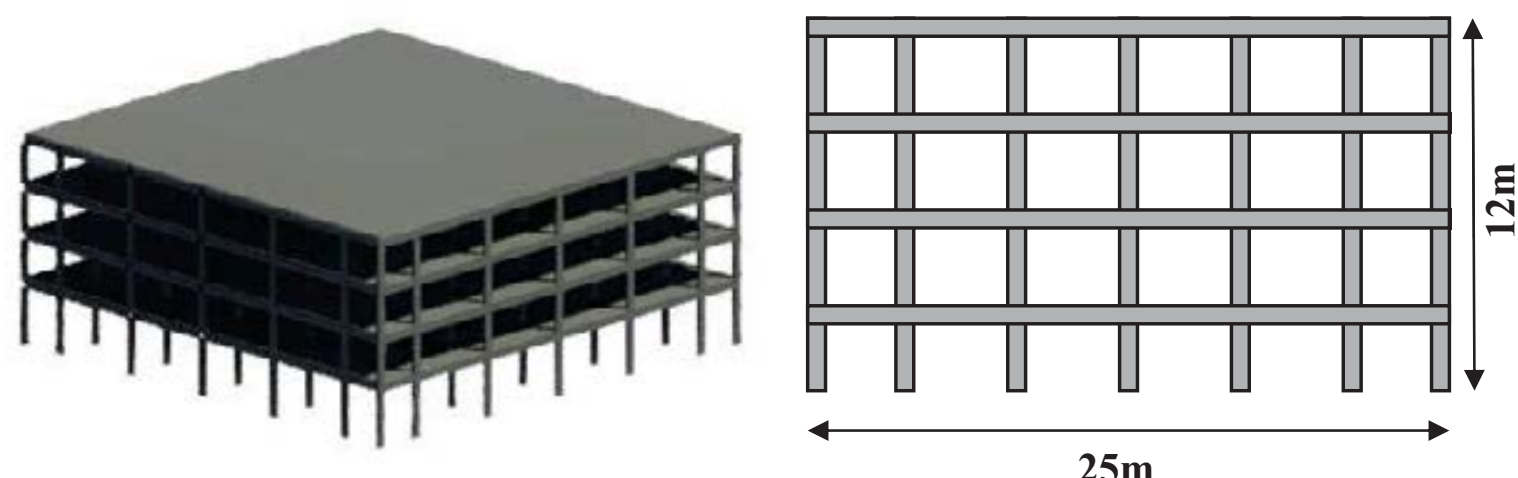

Figure 2: Selected targeted building model in 3D and elevation views.

\subsection{Repeated ground motion selection}

Many studies have considered the impact of repetitive earthquake-induced ground motions on the responsive behaviour of the structures. They found that both the inelastic displacement ratio and its inter-storey drift ratio were significantly influenced by the occurrence of frequent earthquakes. Therefore, in this study, the impact of repeated earthquakes is recognised.

Two real seismic sequences were allocated to each of the ground motion records, namely Chalfant Valley (July 1986 - two events), Imperial Valley (October 1979 - two events) and Mammoth Lakes (May 1980 - two events) from the same station with various record names. For each occurrence, each single ground motion record had a time interval of $15 \mathrm{sec}$. A gap time interval of $100 \mathrm{sec}$ was added between the two consecutive seismic occurrences. As proposed by Hatzigeorgiou and Liolios [27], this gap had zero spite of potential acceleration values and was completely sufficient to reduce the displacement of any structure due to attenuating and returning to the remaining condition. The three repetitive events were selected from the Pacific Earthquake Engineering Research Center (PEER) database. The selected magnitude (Mw) was between 5 and 7 Richter scale, and of intensity measure, PGA ranges between $0.113 \mathrm{~g}$, and $0.447 \mathrm{~g}$ as shown in Figure 3. 
Nevertheless, to perform the IDA and establish fragility surfaces or curves, the selection of appropriate ground motion records are very critical as recommended by international standard codes, such as FEMA356, UBC1997, IBC2000, and others [28-30]. These standard provisions also recommended to select a minimum of three ground motion records, or seven to develop a vulnerability assessment analysis. Finally, the selected earthquake events were scaled based on UBC97 target spectrum where the building was located.
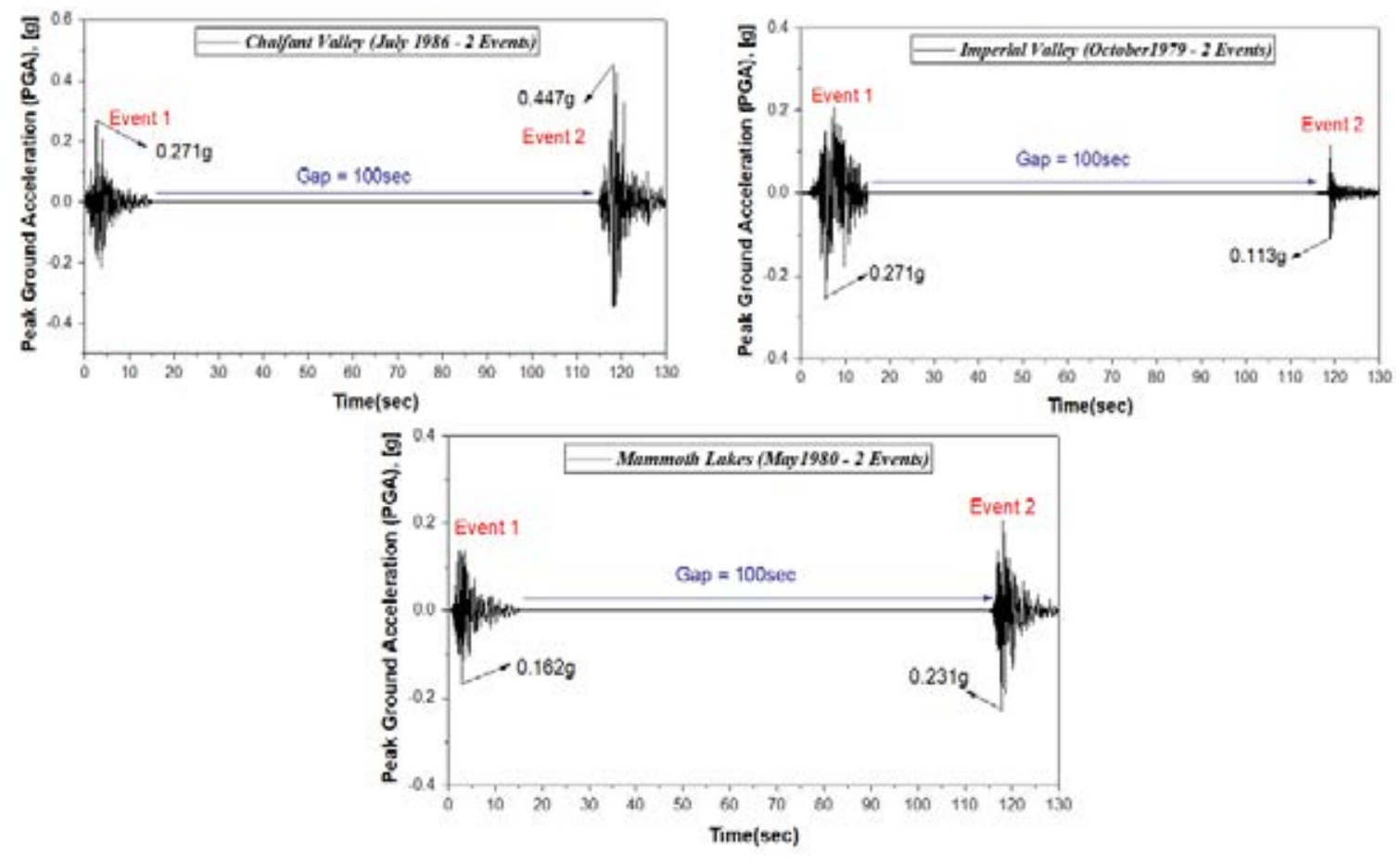

Figure 3: Selection of repeated ground motion seismic events.

\subsection{Seismic resilience index functionality assessment procedure}

Resilience is a specific consideration for evaluating the seismic resistance of the structures and infrastructures, as based on the Multidisciplinary Center for Earthquake Engineering Research (MCEER). Resilience is quantified ranging from $0 \%$ to $100 \%$ in terms of functionality to be normalised into 0 and 1 to develop its SRI, whereby $0 \%$ means spectacular failure and $100 \%$ reveals no structure deterioration. It is a wealth of information to develop the SRI as seismic indicator and a recovery application that can help to reduce direct and indirect losses caused by earthquakes.

The SRI is defined as the functionality of a structure after the recovery process or the ability of a structure to withstand earthquakes without any reduction in its functionality [31]. Also, the SRI can be treated as an alternative to deal with the problem of functionality which has been neglected in the seismic codes [32]. Therefore, the SRI is determined by referring to the functionality curves as shown in Figure 4. The area under the curve of functionality demonstrated the structure's resilience, whereby, the functionality of the structure was represented as $Q(t)$, as illustrated in Equation (1), and the resilience $(R)$ as a function of $Q(t)$ and time of event $\left(t_{O E}\right)$ with recovery time $\left(T_{R E C}\right)$ along the total control time $\left(T_{L C}\right)$, as shown in Equation (2). 
Functionality :

$$
Q(t)=1-\left\{L\left(I, T_{R E C}\right) \times\left[H\left(t-t_{O E}\right)-H\left(t-\left(t_{O E}+T_{R E C}\right)\right] \times f_{R E C}\left(t, t_{O E}, T_{R E C}\right)\right\}\right.
$$

Resilience (R):

$$
R=\int_{T_{O E}}^{T_{R E C}} \frac{Q(t)}{T_{L C}}
$$

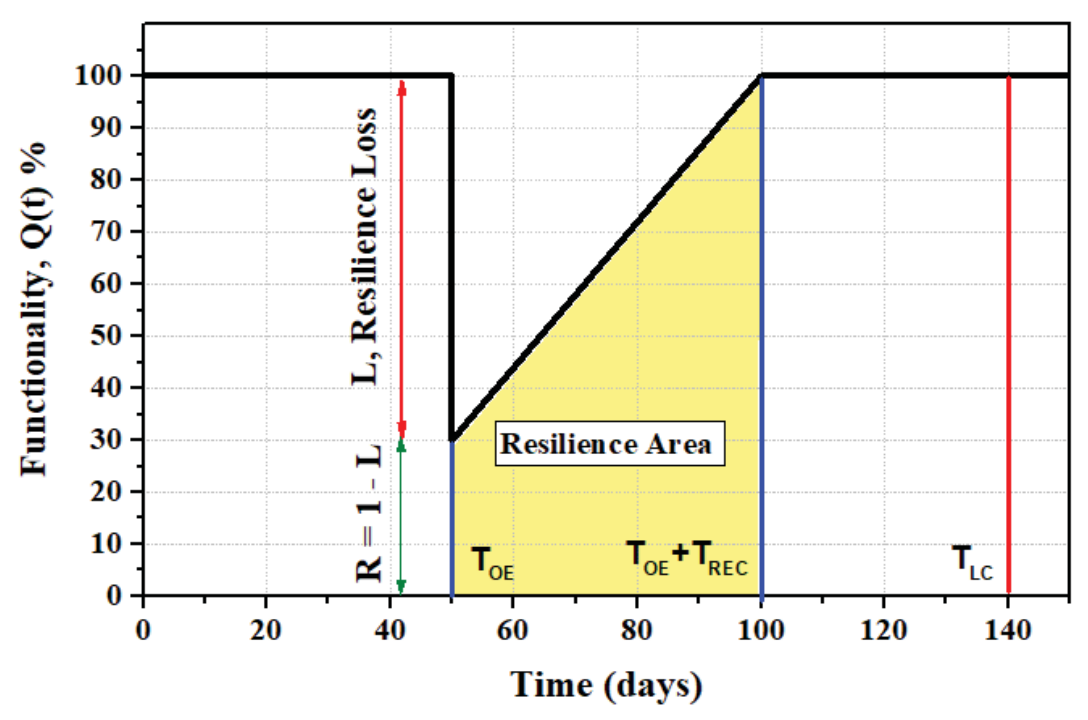

Figure 4: Seismic Resilience with respect to time: Functionality curve.

\subsection{Loss function evaluation}

Losses are very unpredictable in an exceptional case, such as a terrorist attack, blast or other man-made catastrophe, and are different for any scenario discussed. The estimation of losses due to seismic activity is usually questionable and unpredictable. However, it is possible to make some common classifications and identify different types of losses.

Generally, the loss feature usually consists of two types of losses, such as direct losses and indirect losses. The direct loss is referred to structural damages and losses, whereas the indirect losses are referred to causalities, social and economic losses. Since the quantitative analysis of indirect financial damage and human casualties, losses is a complicated procedure, a lot of attention was given to the direct loss in this analysis, as it ultimately depends on the risk of the extensive structural damage.

The direct loss was calculated by using Equation (3) which was required to find the discrete damage probability of four damage states from the fragility surface as a vulnerability analysis. As per FEMA356, by taking into consideration the vertical and horizontal lateral-force resisting components, the state of structural damage during the earthquake determined the performance and output level of a building. These four-performance levels were classified and determined based on \% Inter-Storey Drift Ratio (\%ISDR) as an Engineering Demand Parameter (EDP). Table 1 describes performance levels of each damage state.

$$
\mathrm{L}_{\mathrm{D}}=\sum \mathrm{P}_{\mathrm{E}}(\mathrm{DS}=\mathrm{K}) \times \mathrm{r}_{\mathrm{K}}
$$


Where $\left(\mathrm{L}_{\mathrm{D}}\right)$ is the direct loss, $(\mathrm{K})$ represents the damage state of each performance level, $P_{E}(D S=K)$ represents the discrete damage probability, $\left(r_{K}\right)$ is the corresponding damage ratio for each limit state and damage state that was taken from HAZUS MR4 [33] technical manual, as shown in Table 2. The discrete damage was calculated from the difference between two cumulative distribution functions corresponded to develop fragility surface for each state, as shown from Equation (4) to Equation (8).

$$
\mathrm{P}[\text { Damage }>\mathrm{DS}]=\phi\left(\frac{\ln (\mathrm{IM})-\lambda}{\varsigma}\right)
$$

Where $\phi$ is the cumulative distribution function, IM is an intensity measure, $\lambda$ is the mean value, and $\varsigma$ is the standard deviation.

$$
\begin{aligned}
& \mathrm{P}[\mathrm{DS}=\mathrm{IO}]=\mathrm{P}[\mathrm{DS}=\mathrm{IO}]-\mathrm{P}[\mathrm{DS}=\mathrm{DC}] \\
& \mathrm{P}[\mathrm{DS}=\mathrm{DC}]=\mathrm{P}[\mathrm{DS}=\mathrm{DC}]-\mathrm{P}[\mathrm{DS}=\mathrm{LS}] \\
& \mathrm{P}[\mathrm{DS}=\mathrm{LS}]=\mathrm{P}[\mathrm{DS}=\mathrm{LS}]-\mathrm{P}[\mathrm{DS}=\mathrm{CP}] \\
& \mathrm{P}[\mathrm{DS}=\mathrm{CP}]=\mathrm{P}[\mathrm{DS}=\mathrm{CP}]
\end{aligned}
$$

\begin{tabular}{ccc}
\hline Damage State (DS) & Damage Description & $\begin{array}{c}\text { \% Inter-Storey } \\
\text { Drift Ratio } \\
\text { (\%ISDR) }\end{array}$ \\
\hline $\begin{array}{c}\text { Immediate Occupancy } \\
\text { (IO) }\end{array}$ & $\begin{array}{c}\text { There is significant damage to the minor struc- } \\
\text { tural elements, but the building stability or lat- } \\
\text { eral ability to resist prior and after the seismic is } \\
\text { unaffected. }\end{array}$ & $1.0 \%$ \\
\hline $\begin{array}{c}\text { Damage Control } \\
\text { (DC) }\end{array}$ & $\begin{array}{c}\text { A certain quantity of repairable damage is ap- } \\
\text { propriate, but the repair cost should be substan- } \\
\text { tially lower than the replacement value. }\end{array}$ & $1.50 \%$ \\
\hline $\begin{array}{c}\text { Life Safety } \\
\text { (LS) }\end{array}$ & $\begin{array}{c}\text { Due to the higher damage, repair is feasible but } \\
\text { economically inefficient and costly. The loss is } \\
\text { moderate, but the structure stays stable. }\end{array}$ & $2.0 \%$ \\
\hline $\begin{array}{c}\text { Collapse Prevention } \\
\text { (CP) }\end{array}$ & $\begin{array}{c}\text { The structure is on the threshold point of local } \\
\text { or complete failure being experienced. }\end{array}$ & $2.50 \%$ \\
\hline
\end{tabular}

Table 1: Damage state performance levels description and its damage measures

\begin{tabular}{cc}
\hline Damage State (DS) & Damage Ratio $\left(\mathbf{r}_{\mathbf{k}}\right)$ \\
\hline Immediate Occupancy (IO) & 0.10 \\
\hline Damage Control (DC) & 0.40 \\
\hline Life Safety (LS) & 0.80 \\
\hline Collapse Prevention (CP) & 1.0 \\
\hline
\end{tabular}

Table 2: HAZUS MR4 technical manual for damage ratios of buildings 


\subsection{Recovery function and time}

The progress and the pattern of the structure's post-seismic event rehabilitation will be represented through recovery functions and time. Therefore, for evaluating seismic resilience, recovery time and recovery function are crucial after a seismic event, hence, it should be precisely measured. There are different types of recovery function that could be selected depending on the system and society preparedness response, for example, three possible recovery functions are: linear, exponential, and trigonometric. Where the recovery improvements of the building vary according to the type of recovery functions, it is included to assess the building's functionality, since each function has its own path of restoration. In this study, the linear function is considered to evaluate the building functionality, whereby it is the simplest function commonly used when there is no information available about crisis management and resources. The equations $(9,10$ and 11) show the different types of functions that may be used to develop the recovery time and its function path.

Linear function:

$$
f_{\text {rec }}\left(t, t_{O E}, T_{R E C}\right)=\left(1-\frac{t-t_{O E}}{T_{R E C}}\right)
$$

Exponential function:

$$
f_{\text {rec }}\left(t, t_{O E}, T_{R E C}\right)=\exp \left(-\frac{\left(t-t_{O E}\right)(\ln 200)}{T_{R E C}}\right)
$$

Trigonometric function:

$$
f_{\text {rec }}\left(t, t_{O E}, T_{R E C}\right)=0.5\left\{1+\cos \left[\Pi \frac{\left(t-t_{O E}\right)}{T_{R E C}}\right]\right\}
$$

\section{RESULTS AND DISCUSSION}

The numerical model of the mid-rise building was developed by using the Finite Element (FE) platform, where the nonlinear time history analysis was generated to develop the incremental dynamic analysis curve. From the IDA curves, the relationship between \%ISDR and spectral acceleration of first periodic mode Sa (T1) could be determined, and thus, it determined the performance level of the structure based on 4-performance limit state as shown in Figure 5. Where the damage of measured Sa (T1) of the repeated earthquakes were increasingly scaled by $0.05 \mathrm{~g}$ until it exceeds $2.0 \mathrm{~g}$, the analysis was stopped due to the instability of the structure. The IDA curves are considered an important parametric tool, which evaluates the dynamic behaviour of the structures. This curve clarifies that the building performance is linearly in rapid changes between the damaged states, by which it tends to undergo into three restoration options that will be taken into consideration during post seismic events. The options are; no action at IO stage, restoration action at DC and LS stage, and replacement action at CP stage.

For example, in case of immediate occupancy, no retrofitting action is needed to be applied before exceeding $0.78 \mathrm{~g}$. However, once it reaches the damage control and life safety stages at $1.24 \mathrm{~g}$, and $1.54 \mathrm{~g}$, respectively, it is recommended to apply a retrofitting action before it reaches the collapsed stage, whereby the replacement action is the only choice at $2.15 \mathrm{~g}$ and more. Table 3 summarises the structural performance levels, and types of preparedness actions.

\begin{tabular}{ccc}
\hline Damage State & $\begin{array}{c}\text { IM of each Damage State- } \\
\text { Sa(T1), }[\mathbf{g}]\end{array}$ & Preparedness Action of each Stage \\
\hline Immediate Occupancy & $0.78 \mathrm{~g}$ & No Action \\
\hline Damage Control & $1.24 \mathrm{~g}$ & Restoration- repairing action \\
\hline Life Safety & $1.54 \mathrm{~g}$ & Restoration- repairing action \\
\hline Collapse Prevention & $2.15 \mathrm{~g}$ & Replacement action \\
\hline
\end{tabular}

Table 3: IM of each damage state and its preparedness actions. 


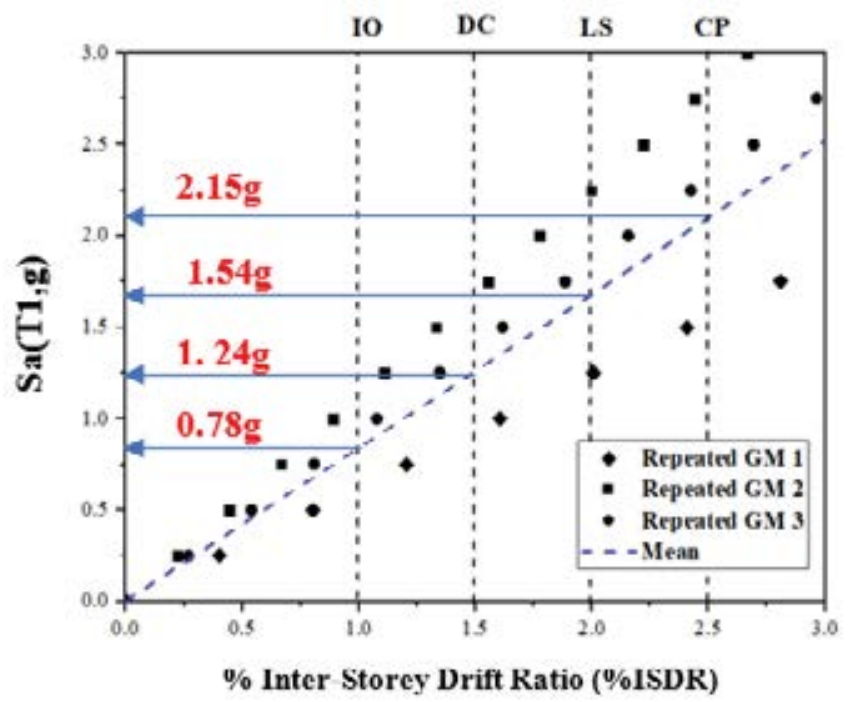

Figure 5: Incremental dynamic analysis curve under repeated earthquakes.

After performing the IDA, the fragility surface and the fragility curve for each damaged state was developed to determine the probability of reaching or exceeding the damaged state at certain Intensity Measure (IM). In this research, the spectral acceleration Sa (T1) was chosen as it was used to perform the nonlinear analysis of time history, as well as the seismic events periodic time was selected as another parameter to be used in developing the fragility surface in order to study the effect of $15 \mathrm{sec}$ seismic events with $100 \mathrm{sec}$ gap between two repetitive earthquakes. The mean and standard deviations are needed to establish the fragility surface assessment as shown in Table 4.

\begin{tabular}{ccccccccc}
\hline Damage State & \multicolumn{2}{c}{ IO } & \multicolumn{2}{c}{ DC } & \multicolumn{2}{c}{ LS } & \multicolumn{2}{c}{ CP } \\
\hline $\begin{array}{c}\text { Log-normal pa- } \\
\text { rameters for mid- } \\
\text { rise building }\end{array}$ & 0.899 & 0.249 & 1.333 & 0.386 & 1.794 & 0.517 & 2.22 & 0.631 \\
\hline
\end{tabular}

Table 4: Log-normal distribution parameters for developing fragility surfaces for each damage state.

Figure 6 presents all set of fragility surface. The study focused on four intensity measures (1.0 $\mathrm{g}, 1.5 \mathrm{~g}, 2.0 \mathrm{~g}$, and $2.5 \mathrm{~g}$ ) for further applying the preparedness actions of recovery in respect to $15 \mathrm{sec}$ of two repetitive seismic events without considering the $100 \mathrm{sec}$ periodic gap. When $1.0 \mathrm{~g}$ ground motion intensity was applied, the building still behaved in the immediate occupancy level with a probability of reaching or exceeding damages of $66 \%$, whereby the rest of the damaged states achieved $19 \%, 6 \%$, and $2.5 \%$ for damage control, life safety, and collapse prevention states, respectively. However, when the structure was exposed to higher intensity measure of $1.50 \mathrm{~g}$, the structure was between two damaged states of damage control and life safety. Whereas, a certain quantity of repairable action was appropriate to be applied with a probability of reaching or exceeding the states of $67 \%$, and $28 \%$, respectively, with slight increases for the collapse stage with $12 \%$ possibility of damage. Furthermore, at intensity measure of $2.0 \mathrm{~g}$, the restoration process was mandatory where the loss was moderate, but the structure stays stable that could be classified at life safety stage with probability of reaching the damage of $65 \%$, and $35 \%$ for collapse prevention state. Finally, with regard to the IDA curves, when the ground motion intensity surpasses $2.0 \mathrm{~g}$, the structure would suffer from extensive damages and the structure would behave on the threshold point of local or complete experienced damage by achieving $100 \%$ probability of damages for the life safety stage. Furthermore, it started to 
face a crucial damage by achieving probability of damages of $66 \%$ at $2.50 \mathrm{~g}$. Therefore, after analysing the structure through the vulnerability examination, starting with IDA, and finishing with the fragility surface, it was clearly identified that due to its ordinary design moment frame system, the building did not have the ability to resist a $15 \mathrm{sec}$ repetitive earthquake. In addition, the implementation of the resilience assessment was important to plan the recovery process for four different damage states by investigating the structure's functional resilience, degradation, robustness, and recovery time post-seismic events. Table 5 represents the percentage of cumulative damage probability of exceedance for the four damage states.
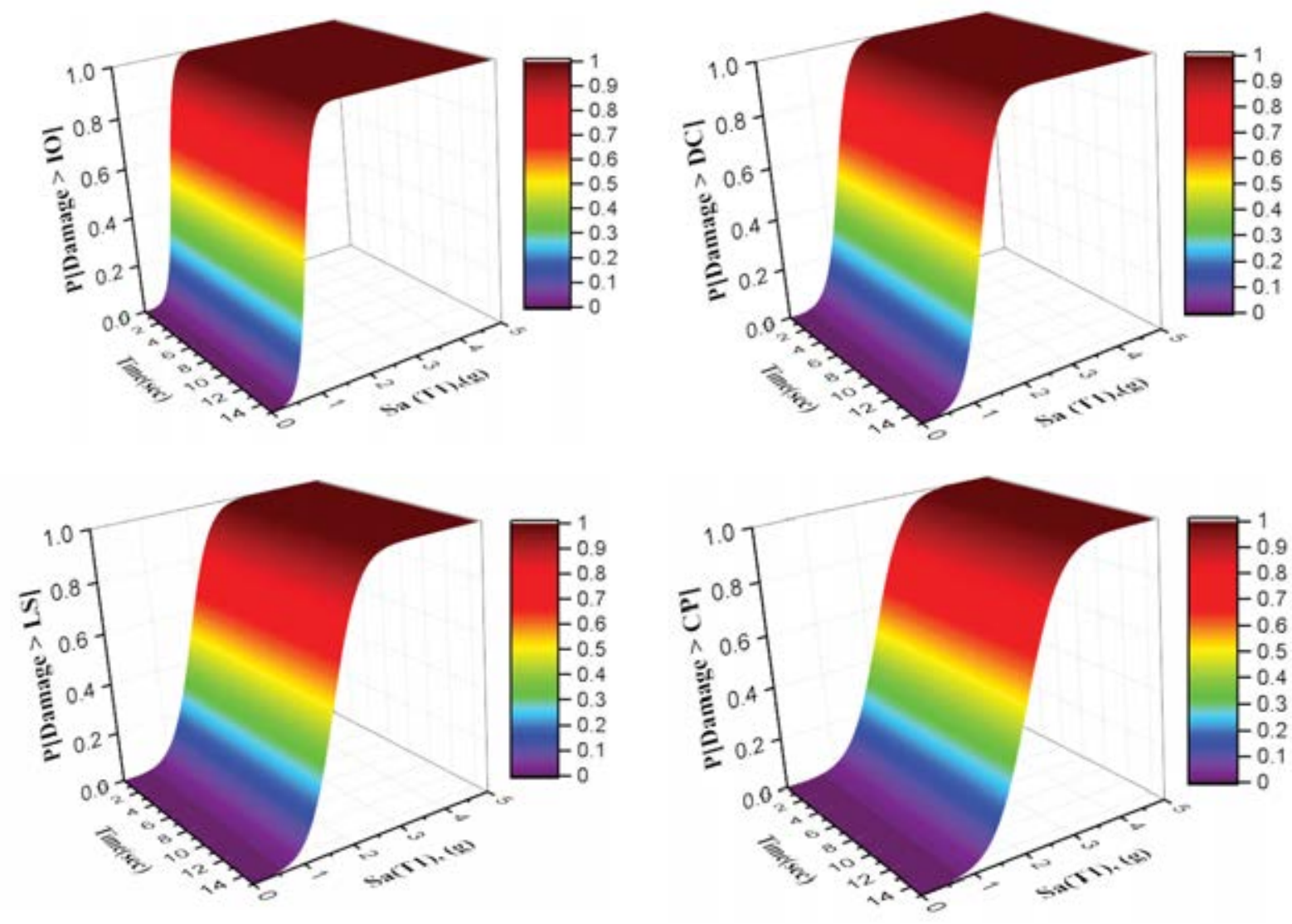

Figure 6: Fragility surfaces for each performance damage state.

\begin{tabular}{ccccc}
\hline Intensity Measure, Sa(T1), Ig] & IO & DC & LS & CP \\
\hline $\mathbf{1 . 0 0 g}$ & $66.00 \%$ & $19.00 \%$ & $6.00 \%$ & $2.50 \%$ \\
\hline $\mathbf{1 . 5 0 g}$ & $99.00 \%$ & $66.00 \%$ & $28.00 \%$ & $12.00 \%$ \\
\hline $\mathbf{2 . 0 0 g}$ & $100 \%$ & $95.00 \%$ & $65.00 \%$ & $36.00 \%$ \\
\hline $\mathbf{2 . 5 0 0 g}$ & $100 \%$ & $100 \%$ & $91.00 \%$ & $66.00 \%$ \\
\hline
\end{tabular}

Table 5: Probability of damage using CDF for each damage state. 
In order to find the SRI and its functionality, the discrete damage probability should be calculated by using Equations (5) to (8). The discrete damage probability was computed from the vulnerability analysis obtained from the fragility surface, known as cumulative distribution function. Table 6 presents the discrete damage probabilities due to post seismic events for each damage state. Subsequently, the direct damage loss $\left(\mathrm{L}_{\mathrm{D}}\right)$ ratio could be computed by the product of $\mathrm{P}_{\mathrm{E}}(\mathrm{DS}=\mathrm{K})$ with the damage ratio $\left(\mathrm{r}_{\mathrm{K}}\right)$ as illustrated in Table 7 .

\begin{tabular}{ccccc}
\hline Intensity Measure, Sa(T1), [g] & IO & DC & LS & CP \\
\hline $\mathbf{1 . 0 0 g}$ & $47 \%$ & $16 \%$ & $4 \%$ & $3 \%$ \\
\hline $\mathbf{1 . 5 0 g}$ & $32 \%$ & $38 \%$ & $16 \%$ & $12 \%$ \\
\hline $\mathbf{2 . 0 0 g}$ & $4 \%$ & $30 \%$ & $30 \%$ & $36 \%$ \\
\hline $\mathbf{2 . 5 0 0 g}$ & $0 \%$ & $9 \%$ & $25 \%$ & $67 \%$ \\
\hline
\end{tabular}

Table 6: Discrete damage probability for different IMs and DS

\begin{tabular}{ccccc}
\hline Intensity Measure, $\mathrm{Sa}(\mathrm{T} 1),[\mathrm{g}]$ & $\mathbf{1 . 0 g}-\mathrm{IO}$ & $\mathbf{1 . 5 g}-\mathrm{DC}$ & $\mathbf{2 . 0 g}-\mathrm{LS}$ & $\mathbf{2 . 5 0 g - C P}$ \\
\hline Direct Loss $\left(\mathrm{L}_{\mathbf{D}}\right)$ & 0.164 & 0.438 & 0.721 & 0.898 \\
\hline
\end{tabular}

Table 7: Direct damage loss ratio for different IM and DS as a preparedness stages

For instance, the time needed for the recovery approach depends on the damage level of the structure. The time required for full recovery was deemed in this study between the time of occurrence $\left(\mathrm{t}_{\mathrm{OE}}\right)$ of seismic event as minimum period, and the control time $\left(\mathrm{T}_{\mathrm{LC}}\right)$ as the maximum period. In this study, the time occurrence was assumed to be taken at the $30^{\text {th }}$ day of the 120 days of the total control period. This study focused on three types of preparedness actions for different retrofitting stages, which were IO, DC, LS, and CP with different intensity measures of $1.0 \mathrm{~g}, 1.50 \mathrm{~g}, 2.0 \mathrm{~g}$, and $2.50 \mathrm{~g}$. These preparedness actions were: No action, retrofitting action, and replacement action based on calculating the SRI and its functionality curve.

At $1.0 \mathrm{~g}$ represented by IO retrofitting stage, the recovery time was set at $37^{\text {th }}$ days which is seven days after earthquake time occurrence to return back to its functionality as before the earthquake. This means that no rehabilitation process needs to be performed. In terms of functionality, the building SRI at this stage was equal to $91.8 \%(0.918)$, with robustness of $83.6 \%$. On the other hand, as the ground motion acceleration becomes higher reaching $1.50 \mathrm{~g}$, which was represented by DC retrofitting stage, the recovery time was set to be at $54^{\text {th }}$ days which was 24 days after seismic action occurrence, which means a simple retrofitting application is needed for restoration process. Whereas, at this stage the SRI decreased to $78.1 \%(0.781)$, with an approximate of $37 \%$ drop in its robustness to $56.2 \%$.

Moreover, at the life safety retrofitting stage with $2.0 \mathrm{~g}$, the recovery time was set at $107^{\text {th }}$ days from total time control which equals to 77 days after the seismic time occurrence. The building requires a quick retrofitting action to be taken before it reaches the collapse stage, with losses of more than $72 \%$ from its robustness, with SRI equals to $64 \%(0.64)$ where the robustness equals to $28 \%$.

Furthermore, at the collapse stage the retrofitting actions was not applicable, because the structure resilience loss exceeded $90 \%$, where the structure robustness equals to $11 \%$. Besides, the recovery time was set at $200^{\text {th }}$ days which was 170 days after time occurrence, which means it exceeded the total time control, and it was beyond control to apply any of the rehabilitation process. In this stage, at $2.50 \mathrm{~g}$ the replacement action was the only option that could be applied, where the building SRI and its functionality equals to $55 \%(0.55)$. Although, during the total 
time control of 120 days, the functionality of the structure equals to $33 \%(0.33)$. Figure 7 shows the variation of functionality curve with respect to time by using the linear function. Furthermore, the shaded area below the functionality curve represented the seismic resilience of the structural system. Table 8 summarises the resilience index, robustness, and losses for each damaged state.
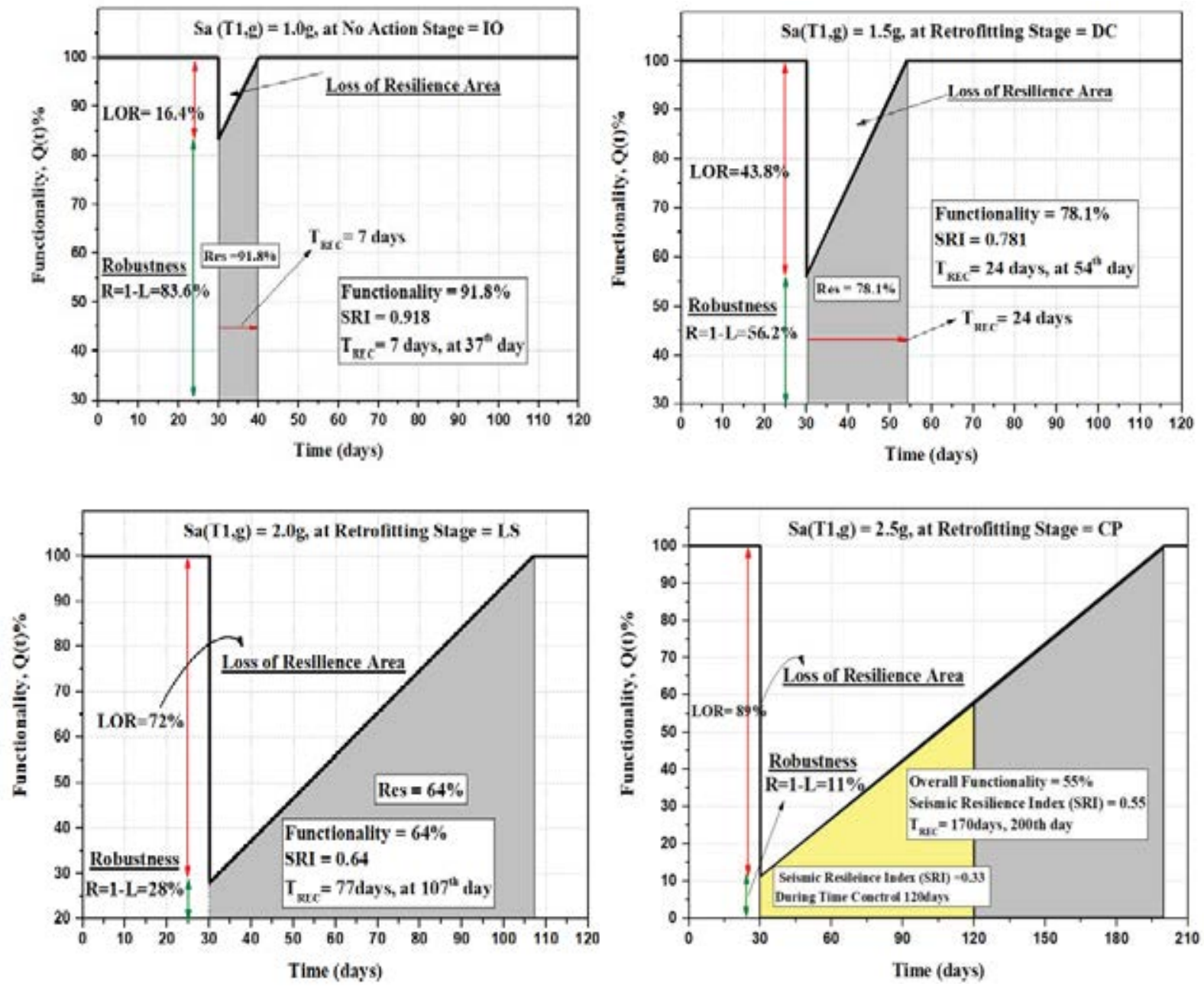

Figure 7: Functionality resilience curves for different preparedness stages.

\begin{tabular}{|c|c|c|c|c|}
\hline Seismic Resilience Outcomes & IO & DC & $\mathbf{L S}$ & $\mathbf{C P}$ \\
\hline Seismic Resilience Index (SRI) & 0.918 & 0.781 & 0.64 & 0.55 \\
\hline Robustness (R) & $83.6 \%$ & $56.2 \%$ & $28 \%$ & $11 \%$ \\
\hline Loss of Resilience (LOR) & $16.4 \%$ & $43.8 \%$ & $72 \%$ & $89 \%$ \\
\hline Time Recovery ( $\left.\mathbf{T}_{\text {REC }}\right)$ & 7 days & 24 days & 77 days & 170 days \\
\hline
\end{tabular}

Table 8: Seismic resilience output results for the targeted building 


\section{CONCLUSION}

The aim of the analysis was to determine the impact of the proposed repetitive seismic acceleration on the seismic resilience capability of the Ordinary Moment Resisting Frame (OMRF) building by applying a set of vulnerability assessment.

- From this analysis, the fluctuation in functionality, resilience index, robustness, structural losses, and time recovery of different performance levels could be predicted with an increase in the potential seismic ground acceleration $(1.0 \mathrm{~g}, 1.50 \mathrm{~g}, 2.0 \mathrm{~g}$, and $2.50 \mathrm{~g})$, which was needed for the post-seismic event strategic recovery planning.

- It could be shown that the increase from $1.0 \mathrm{~g}$ to a maximum of $2.50 \mathrm{~g}$ as a seismic intensity measure for different damaged states resulted in a substantial increasing trend in the damage loss ratio that further influenced the structure's functionality. As well as it increases the time recovery for the structure to compensate its strength as before the seismic event.

- The disparity in seismic resilience demonstrated the effect of ductility capability and demand ductility of the OMRF structure at the post-seismic event for the various ground accelerations.

- The outcomes showed that despite the performance level, the seismic resilience for different damaged states had to be taken into consideration to assess the seismic vulnerability and functionality of the structural behaviour.

\section{ACKNOWLEDGMENT}

This research was funded under the Research University Individual (RUI) Grant Scheme (8014080).

\section{REFERENCES}

[1] Cimellaro, G.P., Reinhorn, A.M. and Bruneau, M., 2010. Framework for analytical quantification of disaster resilience. Engineering structures, 32(11), pp.3639-3649.

[2] Irajifar, L., Alizadeh, T. and Sipe, N., 2013, May. Disaster resiliency measurement frameworks: State of the art. In S. Kajewski, K. Manley, \& K. Hampson. Presented at the World Building Congress, Brisbane, Australia.

[3] Cimellaro, G.P., Solari, D. and Bruneau, M., 2014. Physical infrastructure interdependency and regional resilience index after the 2011 Tohoku Earthquake in Japan. Earthquake Engineering \& Structural Dynamics, 43(12), pp.1763-1784.

[4] Bruneau, M., Chang, S.E., Eguchi, R.T., Lee, G.C., O'Rourke, T.D., Reinhorn, A.M., Shinozuka, M., Tierney, K., Wallace, W.A. and Von Winterfeldt, D., 2003. A framework to quantitatively assess and enhance the seismic resilience of communities. Earthquake spectra, 19(4), pp.733-752.

[5] Bruneau, M. and Reinhorn, A., 2007. Exploring the concept of seismic resilience for acute care facilities. Earthquake Spectra, 23(1), pp.41-62.

[6] Samadian, D., Ghafory-Ashtiany, M., Naderpour, H. and Eghbali, M., 2019. Seismic resilience evaluation based on vulnerability curves for existing and retrofitted typical RC school buildings. Soil Dynamics and Earthquake Engineering, 127, p.105844. 
[7] Vona, M., Mastroberti, M., Mitidieri, L. and Tataranna, S., 2018. New resilience model of communities based on numerical evaluation and observed post seismic reconstruction process. International journal of disaster risk reduction, 28, pp.602-609.

[8] Titi, A. and Biondini, F., 2013, June. Resilience of concrete frame structures under corrosion. In 11th International Conference on Structural, Safety \& Reliability (pp. 16-20).

[9] Alipour, A. and Shafei, B., 2016. Seismic resilience of transportation networks with deteriorating components. Journal of Structural Engineering, 142(8), p.C4015015.

[10] Banerjee, B. and Chandrasekaran, B., 2013. A framework of voronoi diagram for planning multiple paths in free space. Journal of Experimental \& Theoretical Artificial Intelligence, 25(4), pp.457-475.

[11] Eghbali, M., Samadian, D., Ghafory-Ashtiany, M. and Dehkordi, M.R., 2020. Recovery and reconstruction of schools after M 7.3 Ezgeleh-Sarpole-Zahab earthquake; part II: Recovery process and resiliency calculation. Soil Dynamics and Earthquake Engineering, 139, p.106327.

[12] Motamed, H., Ghafory-Ashtiany, M., Amini-Hosseini, K., Mansouri, B. and Khazai, B., 2020. Earthquake risk-sensitive model for urban land use planning. Natural Hazards, 103, pp. $87-102$.

[13] Mastroberti, M. and Vona, M., 2017. New seismic risk index for existing buildings. In 6th ECCOMAS Thematic Conference on Computational Methods in Structural Dynamics and Earthquake Engineering, COMDYN.

[14] Uchida, N. and Bürgmann, R., 2019. Repeating earthquakes. Annual Review of Earth and Planetary Sciences, 47, pp.305-332.

[15] Amadio, C., Fragiacomo, M. and Rajgelj, S., 2003. The effects of repeated earthquake ground motions on the non-linear response of SDOF systems. Earthquake engineering \& structural dynamics, 32(2), pp.291-308.

[16] Oyguc, R., Toros, C. and Abdelnaby, A.E., 2018. Seismic behavior of irregular reinforced-concrete structures under multiple earthquake excitations. Soil Dynamics and Earthquake Engineering, 104, pp.15-32.

[17] Panchireddi, B. and Ghosh, J., 2019. Cumulative vulnerability assessment of highway bridges considering corrosion deterioration and repeated earthquake events. Bulletin of earthquake engineering, 17(3), pp.1603-1638.

[18] Uchida, N., 2019. Detection of repeating earthquakes and their application in characterizing slow fault slip. Progress in Earth and Planetary Science, 6(1), pp.1-21.

[19] El-Maissi, A.M., Argyroudis, S.A. and Nazri, F.M., 2021. Seismic Vulnerability Assessment Methodologies for Roadway Assets and Networks: A State-of-the-Art Review. Sustainability, 13(1), p.61.

[20] Kassem, M. M., Nazri, F. M., \& Farsangi, E. N. 2020. The seismic vulnerability assessment methodologies: A state-of-the-art review. Ain Shams Engineering Journal, 11(4), pp. 849-864.

[21] Gehl, P., Seyedi, D., Douglas, J. and Khiar, M., 2009, June. Introduction of fragility surfaces for a more accurate modeling of the seismic vulnerability of reinforced concrete structures. In COMPDYN 2009-ECCOMAS Thematic Conference on Computational Methods in Structural Dynamics and Earthquake Engineering. 
[22] Martin, J., Alipour, A. and Sarkar, P., 2019. Fragility surfaces for multi-hazard analysis of suspension bridges under earthquakes and microbursts. Engineering Structures, 197, p.109169.

[23] Kassem, M. M., Nazri, F. M., \& Farsangi, E. N. 2020. On the quantification of collapse margin of a retrofitted university building in Beirut using a probabilistic approach. Engineering Science and Technology, an International Journal, 23(2), 373-381.

[24] Hariri-Ardebili, M.A. and Saouma, V.E., 2016. Collapse fragility curves for concrete dams: comprehensive study. Journal of Structural Engineering, 142(10), p.04016075.

[25] Hariri-Ardebili, M.A. and Saouma, V.E., 2016. Seismic fragility analysis of concrete dams: A state-of-the-art review. Engineering Structures, 128, pp.374-399.

[26] Gehl, P., Sy, S. and Seyedi, D., 2011, May. Developing fragility surfaces for more accurate seismic vulnerability assessment of masonry buildings. In COMPDYN-3rd Int. Conf. on Computational Methods in Struct. Dynam. \& Earthq. Eng.

[27] Hatzigeorgiou, G. D., \& Liolios, A. A. (2010). Nonlinear behaviour of RC frames under repeated strong ground motions. Soil dynamics and earthquake engineering, 30(10), 1010-1025.

[28] FEMA-356. 2000. Commentary for the seismic rehabilitation of buildings. Washington, D.C.: Federal Emergency Management Agency, FEMA-356.

[29] UBC. 1997. Structural design requirement, Division IV. Earthquake Design, 2(1), 9-37.

[30] IBC. 2000. International Building Code, International Code Council. Inc. (formerly BOCA, ICBO and SBCCI), 1-796.

[31] Motlagh, Z. S., Dehkordi, M. R., Eghbali, M., \& Samadian, D. 2020. Evaluation of seismic resilience index for typical RC school buildings considering carbonate corrosion effects. International journal of disaster risk reduction, 46, 101511.

[32] Yu, P., Wen, W., Ji, D., Zhai, C., \& Xie, L. 2019. A framework to assess the seismic resilience of urban hospitals. Advances in Civil Engineering, 2019.

[33] HAZUS, MR4 Technical manual. 2003. Multihazard loss estimation methodology. Washington DC, USA: Department of homeland society. 